\title{
Up and down
}

\author{
The upper atmosphere is not at the focus of public attention. Yet it is becoming clear that human-induced \\ changes reach high above Earth's surface, with potential repercussions down below.
}

Much of the Earth system is arranged in layers. It is often at the interface between these layers that geoscience becomes interesting. For example, the flow of heat between the Earth's core and mantle can tell us about the vigour of thermal plumes in the mantle, as well as the evolution of the inner core ${ }^{1}$. The movement of mantle rocks through the transition zone between the lower and upper mantle may change their chemical composition, and affect the makeup of the upper mantle ${ }^{2}$. And the strength of the ocean overturning circulation, which links the ocean's wind-churned surface layer with the deep sea, determines how much heat and carbon are sequestered in the ocean's abyss ${ }^{3}$.

Likewise in the atmosphere, the exchange of air across the tropopause, the transition zone between the lowest level of the atmosphere and the layer immediately above, plays a key role in the distribution of greenhouse gases and other air constituents. The composition of air above the tropopause is greatly affected by updrafts from the lower atmosphere, particularly in the tropics. Upper air composition matters: it encompasses (among other constituents) ozone, which protects the Earth's surface from damaging ultraviolet radiation, as well as water vapour, a potent greenhouse gas. A Review on page 169 concludes that the upward transport of air from the lower layer (the troposphere) into the upper layer (the stratosphere) is likely to be strengthened by climate change.

A human 'fingerprint' in the stratosphere is nothing new. The discovery of the ozone hole in 1985 firmly demonstrated that human-made substances that are released at the Earth's surface can make their way up into the stratosphere, and wreak havoc with fundamental processes of the planet. If the transfer of air from the troposphere to the stratosphere speeds up in a changing climate as proposed, human-made pollutants and disturbances will go upwards ever quicker. Already, rising carbon dioxide concentrations - ultimately attributable to emissions on the ground - have been detected in the thermosphere ${ }^{4}$, two atmospheric layers above the stratosphere, at an altitude of about $100 \mathrm{~km}$.

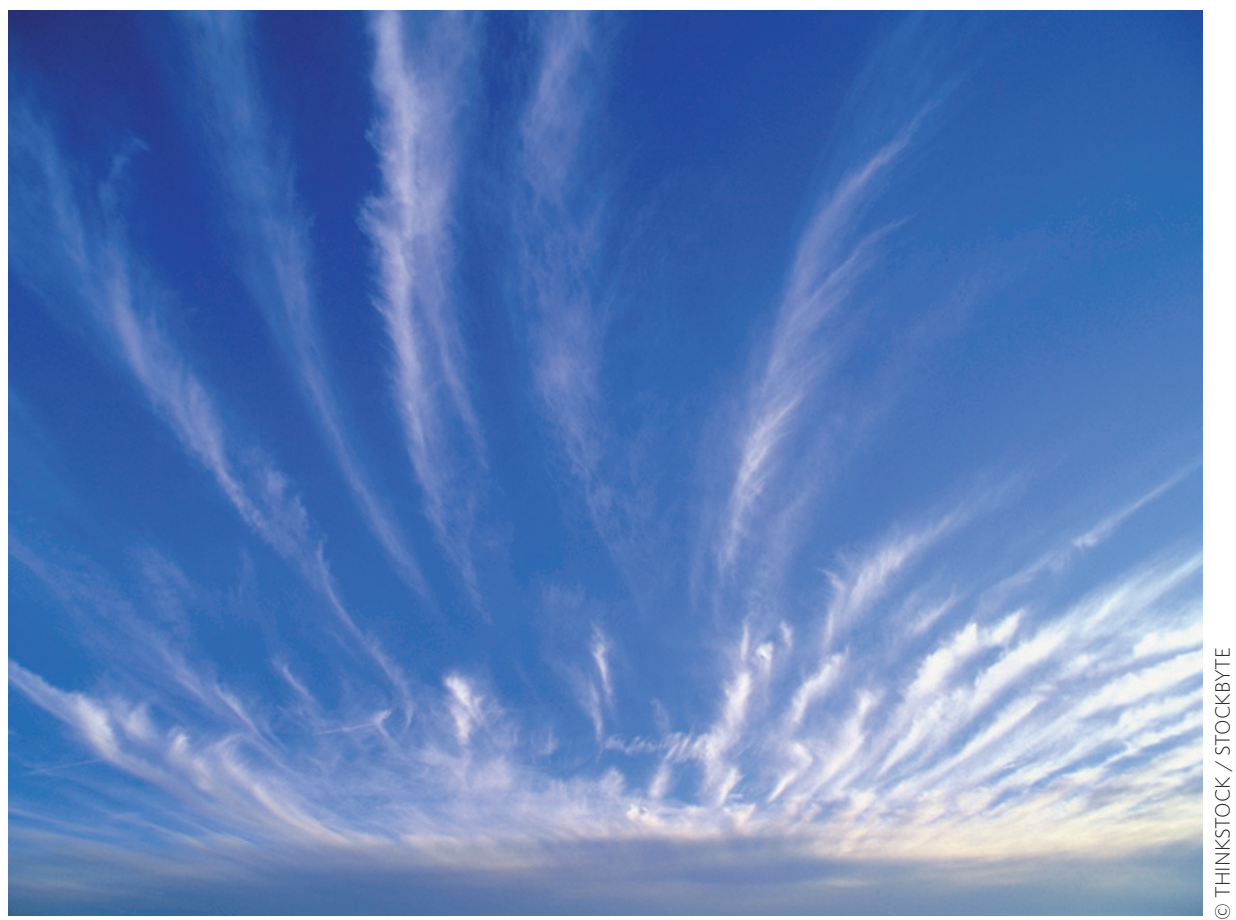

A change in atmospheric composition so high up may seem of little consequence, except perhaps for uppermost air density, and hence the lifespan of satellites. From today's point of view, this may be true. But influences from above can take time to discover. The stratosphere at least, located at altitudes between about 12 and $50 \mathrm{~km}$, has turned out to influence Earth's surface more profoundly than once thought.

In the Northern Hemisphere, stratospheric dynamics affect the North Atlantic Ocean circulation ${ }^{5}$ and climate teleconnections between the Pacific and Europe ${ }^{6}$. Likewise in the Southern Hemisphere, the ozone hole does not influence only the levels of incoming ultraviolet radiation. Together with greenhouse warming, it also alters the southern westerly wind systems ${ }^{7}$, summer climate ${ }^{8}$ and the Southern Ocean's ability to take up trace gases from the atmosphere 9

In the 1990s, climate scientists took great pains to explain to a bemused public that the ozone hole and climate change although both a result of human action
- were separate phenomena, with distinct causes and effects and operating largely at different layers of the atmosphere. Emissions of chlorofluorocarbons and carbon dioxide are, of course, still the distinct ultimate causes of ozone depletion and climate warming, respectively. But we now know that the ozone hole and climate warming are also closely intertwined, as are the relevant atmospheric layers.

Taking this insight seriously, we should monitor very closely what goes up into the atmosphere. Changes up high may well come back down to the human sphere.

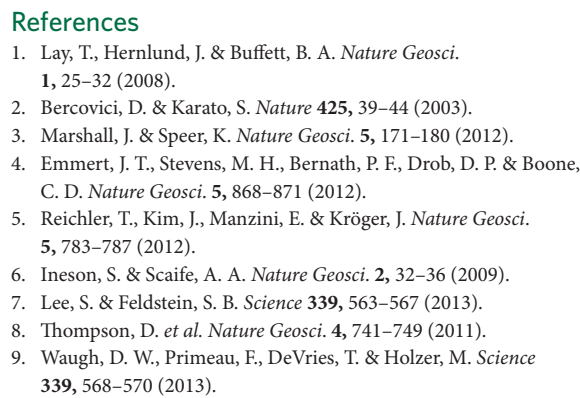

